\title{
Meteotsunami observed in Japan following the Hunga Tonga eruption in 2022 investigated using a one-dimensional shallow-water model
}

\author{
Shion Sekizawa ${ }^{1}$, and Tsubasa Kohyama ${ }^{2}$ \\ ${ }^{1}$ Research Center for Advanced Science and Technology, the University of Tokyo, Tokyo, Japan \\ ${ }^{2}$ Department of Information Sciences, Ochanomizu University, Tokyo, Japan \\ (Corresponding author: Shion Sekizawa, RCAST, the University of Tokyo, Japan. \\ E-mail: shion@atmos.rcast.u-tokyo.ac.jp)
}

* This manuscript has been submitted for publication in Scientific Online Letters on the Atmosphere
(SOLA). It is not yet peer-reviewed. Subsequent versions of this manuscript may have slightly different
content. If accepted, the final version of this manuscript will be available via a link on this webpage.

\begin{abstract}
On January 15, 2022, the volcano Hunga Tonga about 8000-km away from Japan explosively erupted. Following the eruption, tsunami-like sea-level fluctuations were observed in Japan, much earlier than expected based on the oceanic long-wave propagation from Tonga to Japan. By contrast, atmospheric pressure disturbance presumably due to the eruption was also observed about 30 minutes before the sea-level change. Therefore, the observed sea-level fluctuations can be considered as meteotsunamis forced by the pressure perturbation rather than tectonically forced by the eruption, but the mechanism is not yet fully understood.

This study attempts to understand the nature of this meteotsunami by using a simple one-dimensional shallow-water model. The results show that the time and amplitude of the observed sea-level changes are consistent with the simulated sea-level changes forced by the atmospheric forcing. A set of experiments with different bathymetry profiles also reveals the importance of amplification due to Proudman resonance over deep basins and the shoaling effect over the continental slope, while extremely deep and narrow topography such as trenches is of second-order importance.
\end{abstract}

\section{Introduction}

At a volcano called Hunga Tonga-Hunga Ha'apai located in the Tonga Islands, a large-scale volcanic eruption occurred at around 1pm on January 15, 2022 (we hereafter use Japan Standard Time as local time). In response to this eruption, the Japan Meteorological Agency (JMA) announced at around $7 \mathrm{pm}$ that some sea-level changes were expected in Japan, but they expected no concern about large fluctuations that could be deadly for human lives or induce societal damages. According to JMA, this announcement was based on the evidence that the magnitude of tsunami events had been limited in other Pacific regions closer to the Tonga Islands.
What actually happened in the real world, however, was different from what we had expected. Figure 1a shows the time series of observed sea levels at Amami $\left(28^{\circ} \mathrm{N}, 129^{\circ} \mathrm{E}\right)$, Ayukawa $\left(38^{\circ} \mathrm{N}\right.$, $\left.141^{\circ} \mathrm{E}\right)$, and Tokyo $\left(35^{\circ} \mathrm{N}, 139^{\circ} \mathrm{E}\right)$ (Fig. 2). These time series exhibit prominent sea-level fluctuations at around $8 \mathrm{pm}$, which presumably means that it has taken 7.5 hours for the information of the eruption to travel about $8,000 \mathrm{~km}$ from the Tonga Islands to Japan. If we assume this information was conveyed by oceanic tsunami waves, whose phase velocity is calculated as $\sqrt{g H}$ where $g$ is the gravitational acceleration and $H$ is the equivalent depth, then $H$ would be about $9,000 \mathrm{~m}$. Considering that the ocean 
a) Observed sea level

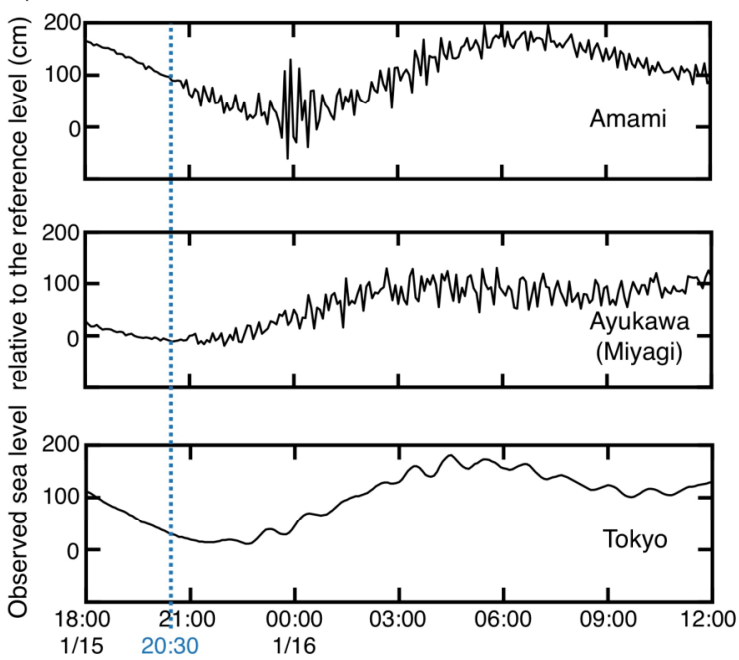

b) Observed surface air pressure

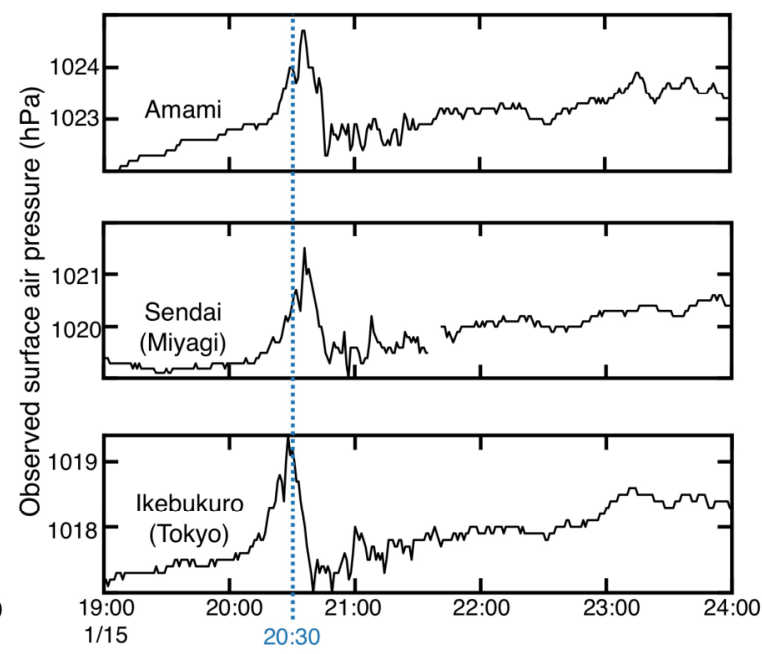

Fig. 1. Time series of observed (a) sea level at three representative sites, and (b) surface pressure at three stations near the locations shown in (a).

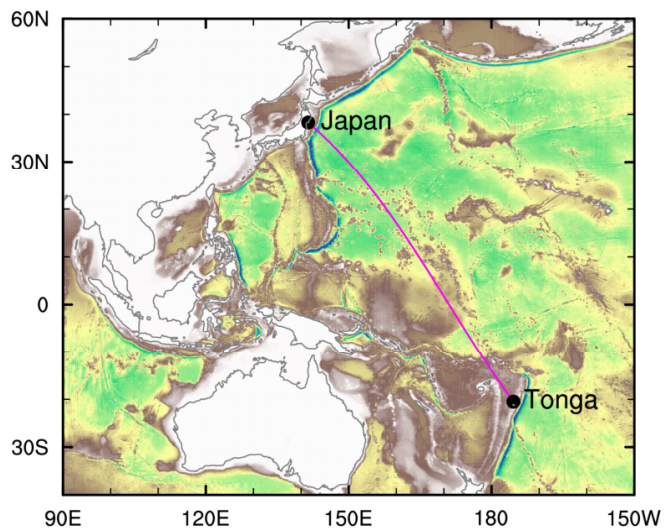

$0 \mathrm{~m}$

$1000 \mathrm{~m}$

$2000 \mathrm{~m}$

$3000 \mathrm{~m}$

$4000 \mathrm{~m}$

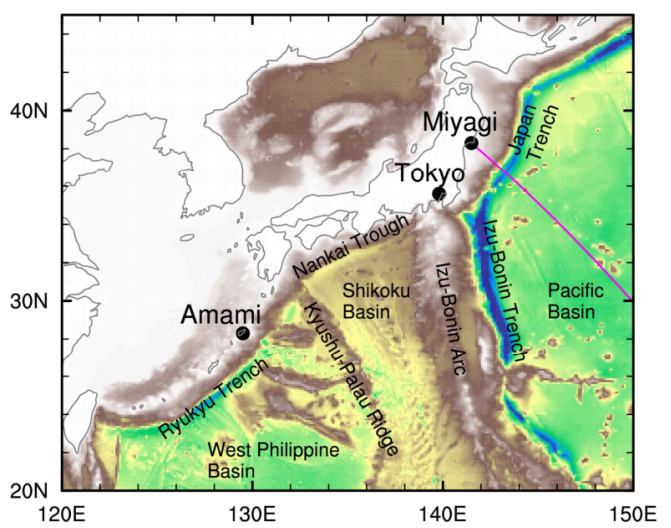

Fig. 2. Ocean bathymetry and geographical locations referred to in this paper. depth between Japan and the Tonga Islands is typically about 5,000 $\mathrm{m}$ (Fig. 2), this equivalent depth is too deep. The sea-level fluctuations were observed too early to be due to tsunami waves directly excited by the eruption. In fact, later in the evening, JMA announced tsunami warnings for some areas in Japan. The observed sea-level fluctuations were earlier and larger than expected, and the mechanism of the sealevel fluctuations is yet to be fully explained.

As a promising mechanism for understanding similar sea-level fluctuations, Press and Harkinder (1966) reported that atmospheric waves generated by the notable volcanic eruption of Krakatoa in 1883 caused large sea-level fluctuations. Their following work, Harkrider and Press (1967), numerically investigated multiple modes of air-sea coupled waves excited by an air pulse produced by the Krakatoa volcano. Their results showed that, even if the oceanic equivalent depth $H$ is fixed, atmospheric free waves with phase velocities close to $\sqrt{g H}$ are capable of transferring energy to the ocean in an efficient manner. In fact, this kind of sea-level fluctuations, which is often referred to as meteotsunamis or Abiki, has already been extensively studied in contexts unrelated to volcanic eruptions (e.g., Hibiya and Kajiura 1982; Fukuzawa and Hibiya 2020; Kubota et al. 2021). The main mechanism of meteotsunami is called the Proudman resonance (Proudman 1929), which is a physical process where pressure perturbations of atmospheric waves amplify oceanic waves that have sufficiently close phase speeds. 
In this study, we hypothesize that the sea-level fluctuations that followed the recent volcanic eruption in the Tonga Islands were caused by atmospheric waves, and present theoretical considerations on whether this hypothesis is consistent with observed evidence. Because the numerical simulations presented in this study are idealized, we cannot immediately conclude that the presented physical process was of first-order importance to explain the sea-level fluctuations observed in the real world. Nevertheless, our purpose is to show that a plausible explanation can be given if atmospheric waves worked as a main forcing source. In particular, we pose the following scientific questions:

- Where on Earth did the Proudman resonance contribute to the sea-level fluctuations most efficiently?

- Could the existence of deep regions such as the ocean trench have been important?

- How could the coastal shallow region and the seafloor topography enhance and/or sustain sea-level fluctuations?

This paper is organized as follows. In section 2, data and methods are presented. In section 3, we will discuss some results obtained from idealized models. In section 4, we will present conclusions.

\section{Data and model}

\subsection{Observations}

The observed sea-level data is from the Realtime Tidal Data archived by Hydrographic and Oceanographic department of Japan Coast Guard available at https://www1.kaiho.mlit.go.jp/TIDE/gauge/ (Accessed: 11:13 am, January 20). The time span used in this study is from $6 \mathrm{pm}$, January 15 , to the following noon, and the time resolution is 5 minutes. The observed air pressure data is from the Soratena meteorological stations owned by Weathernews Inc., which is distributed for free for academic use. The detailed description of the data is presented at https://jp.weathernews.com/news/38708/ (in Japanese). The time span used in this study is from $7 \mathrm{pm}$, January 15 , to the following midnight, and the time resolution is 1 minute.

\subsection{Simple shallow-water model}

To investigate the oceanic response to atmospheric pressure waves, we have conducted numerical experiments with a simple one-dimensional model. A set of fundamental equations of the model is the linearized, non-rotating shallow-water equations:

$$
\left\{\begin{array}{l}
\frac{\partial \eta}{\partial t}=-\frac{\partial}{\partial x}(u H) \\
\frac{\partial u}{\partial t}=-g \frac{\partial \eta}{\partial x}-\frac{1}{\rho} \frac{\partial P}{\partial x}
\end{array}\right.
$$

where $\eta(t, x)$ and $u(t, x)$ are the sea-level change from its mean state and the current velocity, respectively, at any time $t$ and location $x$ on the Cartesian coordinates. $\rho$ and $g$ are the density of seawater $(1027 \mathrm{~kg}$ $\left.\mathrm{m}^{-3}\right)$ and gravitational acceleration $\left(9.81 \mathrm{~m} \mathrm{~s}^{-2}\right)$, respectively. We have integrated Eq. (1) by the leapfrog scheme from the rest state over the $10,000-\mathrm{km}$ long domain $(-2,000 \mathrm{~km} \leq x \leq 8,000 \mathrm{~km})$ as illustrated in Fig. 3. The boundary condition is $u=0$ at $x=2,000$ and $8,000 \mathrm{~km}$, although it may overemphasize the amplitude of sea-level fluctuations at the boundaries. We consider the boundary at $x=8,000 \mathrm{~km}$ as the coast of Japan and focus on only the domain $0 \leq x \leq 8,000$ $\mathrm{km}$. Around the opposite boundary at $x=-2,000 \mathrm{~km}$, strong linear damping is applied to attenuate reflected waves.

The atmospheric pressure forcing $P$ is imposed as an external forcing and assumed to be a period of sinusoidal function as

$$
\begin{aligned}
& P(t, x)= \\
& \left\{\begin{aligned}
& P_{0} \sin \left[\frac{2 \pi}{L}(x-V t)\right] \\
& \text { in } V t-L / 2 \leq x \leq V t+L / 2, \\
& 0 \text { elsewhere, }
\end{aligned}\right.
\end{aligned}
$$

where the amplitude $P_{0}$, wavelength $L$ and propagation speed $V$ are prescribed as $2 \mathrm{hPa}, 500 \mathrm{~km}$ and 310 $\mathrm{m} \mathrm{s}^{-1}$, respectively, in accordance with observations in Japan (see section 3.1). At $t=0$, the center of the pressure disturbance is located $8000-\mathrm{km}$ away from the coast $(x=0)$, which is approximately equal to the distance between Tonga and Japan. In reality, both atmospheric and oceanic waves propagate on a sphere, rather than on a plane with Cartesian coordinates. Nevertheless, we consider that the difference in the coordinate system does not seriously affect the results, since the effect of ocean topography relatively close to Japan is important as we see later.

We have designed six experiments with different bathymetry profiles $H(x)$ as indicated in Figs. 4 


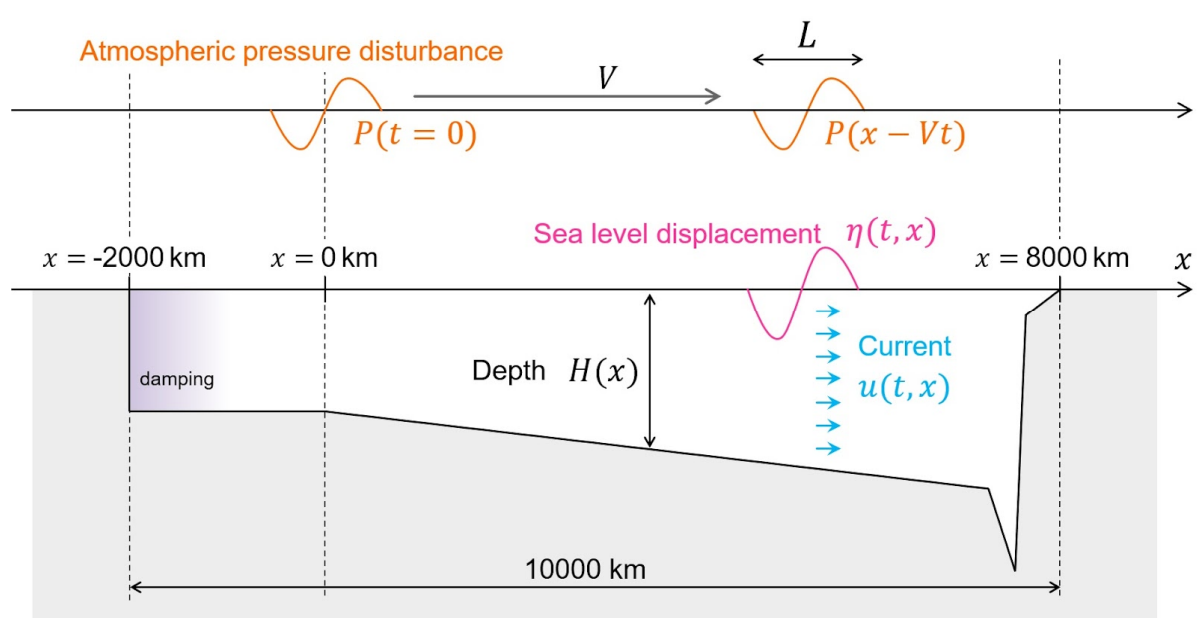

Fig. 3. Schematic of the one-dimensional shallow-water model used in this study. See the text for details.

and 5 (black lines): realistic bathymetry (RB), idealized bathymetry (IB), 6,000-m flat floor (FF60), 4,500-m flat floor (FF45), no trench (NoT), and no shelf (NoS). In the RB experiment, $H(x)$ has been taken from the real bathymetry along the great circle between Tonga and Japan (Fig. 2) based on the General Bathymetric Chart of the Oceans (GEBCO)'s 2021 gridded data (https://doi.org/10.5285/c6612cbe50b3-0cff-e053-6c86abc09f8f). The bathymetry is simplified in the IB experiment to represent deepening ocean basin, trench, and steep continental slope. The two flat floor experiments, FF60 and FF45, have flat seafloors of 6,000 and $4,500 \mathrm{~m}$, respectively. The NoT and NoS experiments exclude domains deeper than $6,000 \mathrm{~m}$ around the trench and shallower than $2,000 \mathrm{~m}$ near the coast, respectively, from the idealized bathymetry.

\section{Results}

\subsection{Observed evidence}

The observed sea-level fluctuations started around 9pm local time, and lasted more than half a day. Figure 1a shows the time series of the sea-lev el fluctuations at three representative sites (Fig. 2). At Amami, the sea-level fluctuations started weakly, and a few hours later, exhibited one of the largest fluctuations in Japan. Sea-level fluctuations are observed even in the inland sea such as the Tokyo station, though it is more moderate than those observed at stations closer to the open ocean. As already shown in the Introduction, such sea-level fluctuations are too early to be considered as tectonically induced tsunamis.
The observed pressure fluctuations arrived in Japan around 8:30 am, which is about 30 minutes earlier than the sea-level fluctuations, and then the fluctuations traveled about 30 minutes across Japan with an amplitude of about $2 \mathrm{hPa}$. Figure $1 \mathrm{~b}$ shows the time series of air pressure fluctuations at three stations near the locations shown in Figure 1a. Because the eruption occurred around $1 \mathrm{pm}$, it is estimated that the pressure fluctuations traveled for less than 8 hours over the $8,000 \mathrm{~km}$ distance from Tonga to Japan. Hence, the phase velocity of the atmospheric waves is estimated to be about $310 \mathrm{~m} \mathrm{~s}^{-1}$, which virtually represents the speed of sound. In addition, since the pressure fluctuations took about 30 minutes to rise and fall, the wavelength is estimated to be about $500 \mathrm{~km}$.

As already shown in section 2, our simulations incorporate the aforementioned observed evidence as a pressure forcing.

\subsection{Simulated sea-level fluctuations}

Figures 4 and 5 (shading) show the time evolutions of simulated sea-level changes in the six experiments. In the RB experiment, many waves propagating in both directions are extensively generated (Fig. 4a). Only the leading rightward wave propagates at the speed of the pressure disturbance $V$ (forced wave), while all other waves at the phase speed of long wave $c=\sqrt{g H}$ (free waves). The rightward free waves emerge not only at $t=0$ but also on the way the forced wave propagates.

If the realistic topography is simplified as in the IB experiment, only a pair of forced and free waves 
(a) Real Bathymetry (RB)
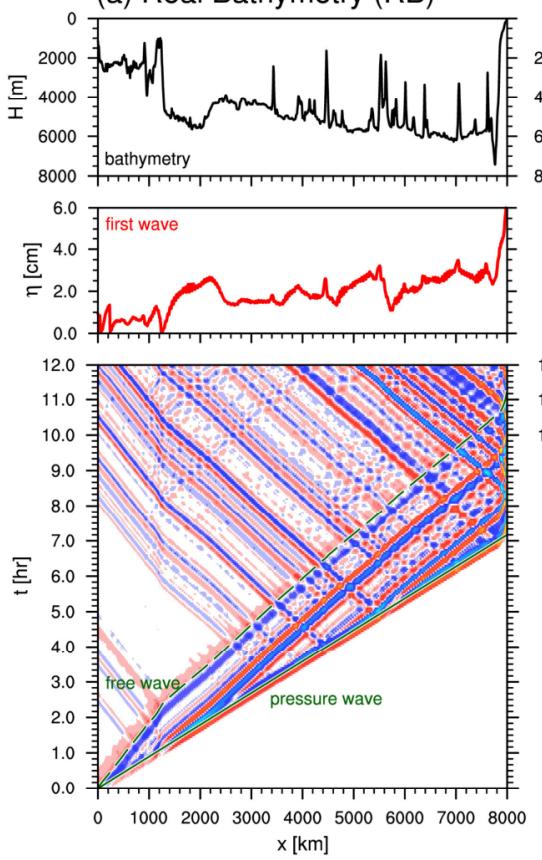

(d) 4,500m Flat Floor (FF45)

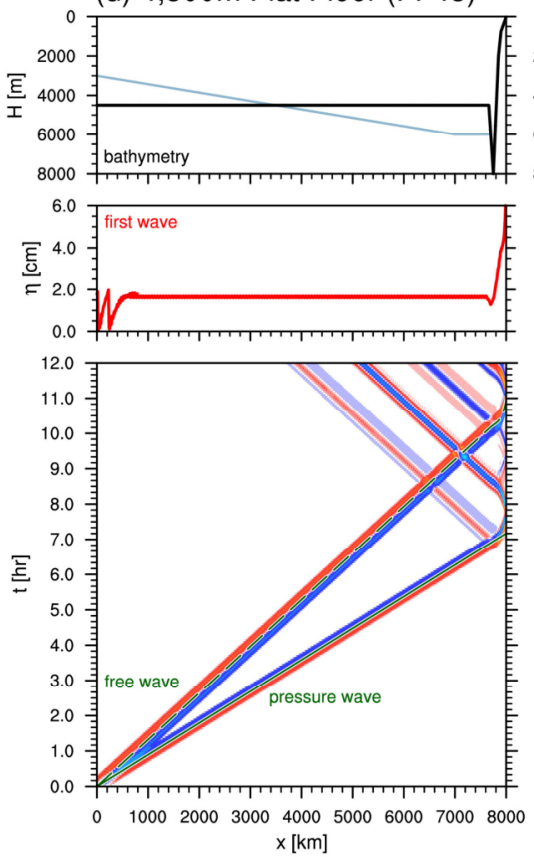

(b) Idealized Bathymetry (IB)
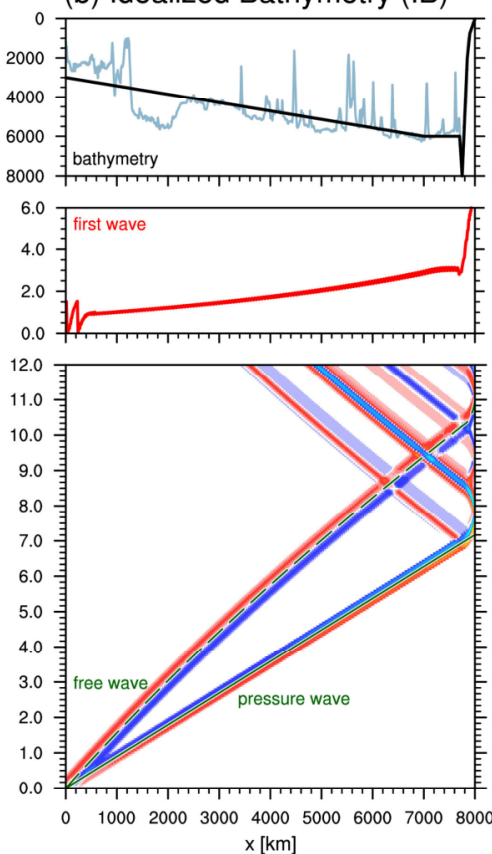

(e) No Trench (NoT)
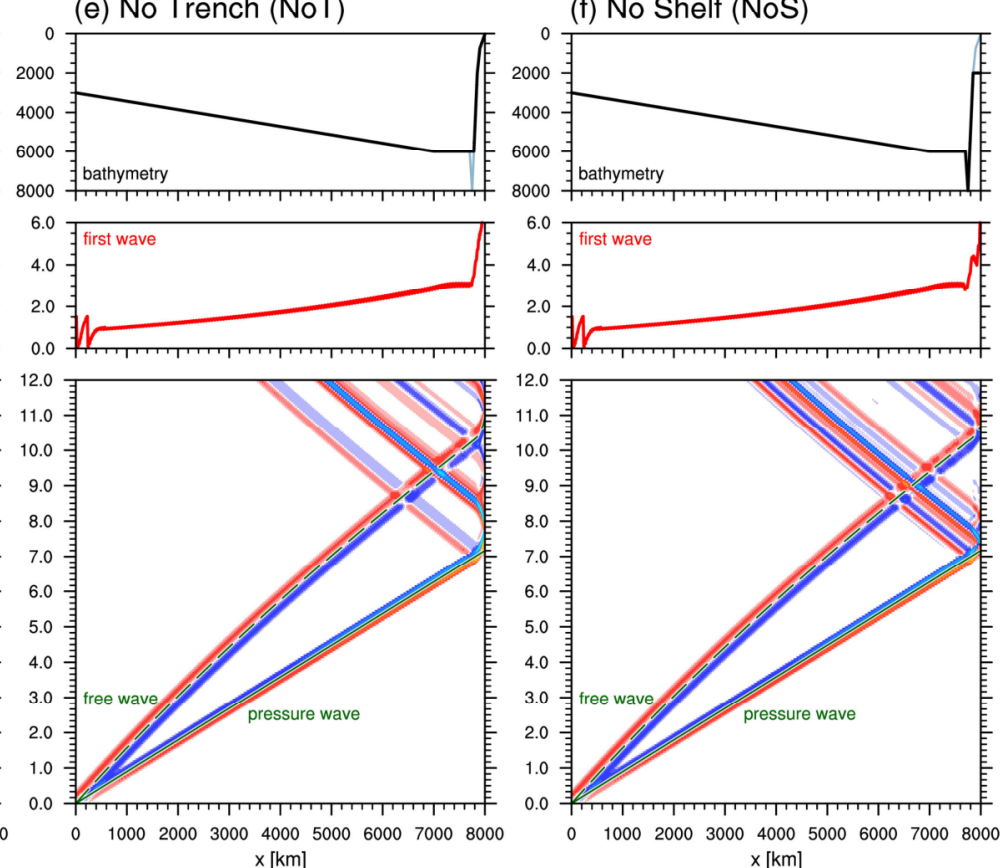

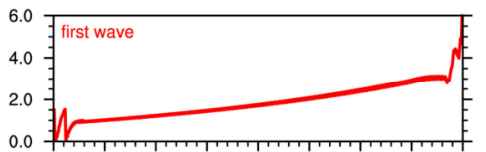

(c) 6,000m Flat Floor (FF60)
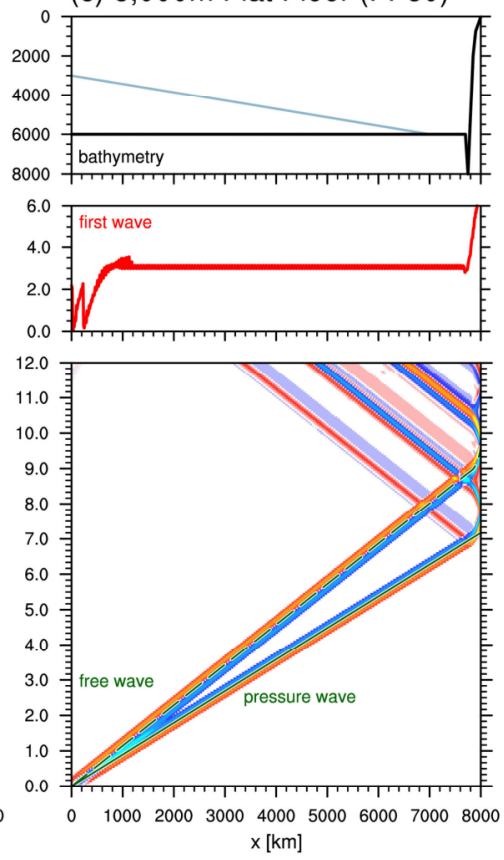

(f) No Shelf (NoS)

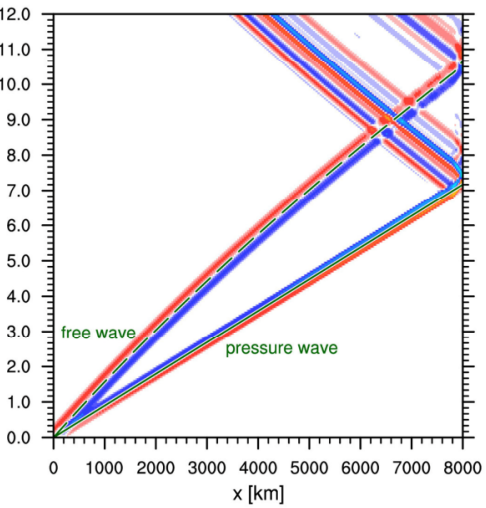

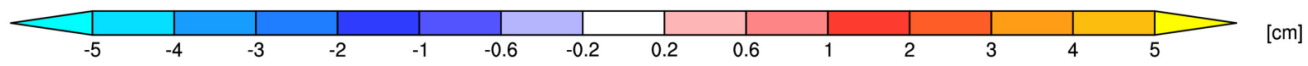

Fig. 4. Prescribed bathymetry profiles (black lines) and simulated sea-level changes (shading) in the (a) RB, (b) IB, (c) FF60, (d) FF45, (e) NoT, and (f) NoS experiments. For each panel, black line in the upper part indicates the prescribed bathymetry, with light blue lines in (b) and in (c-f) indicating that of the RB experiment and IB experiment, respectively. Red line in the middle part of each panel denotes the amplitude of the first wave as a function of $x$. The lower part illustrates Hovmöller diagram of the simulated sea-level change, with green solid and dashed lines indicating travel-time curves of the pressure wave and the free wave that departs from $x=0$ at $t=0$. 
(a) Real Bathymetry (RB)
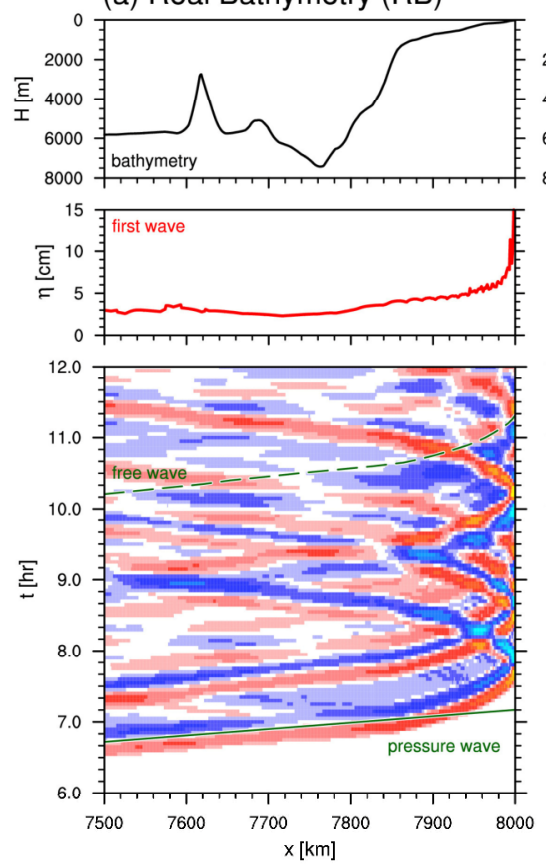

(d) 4,500m Flat Floor (FF45)
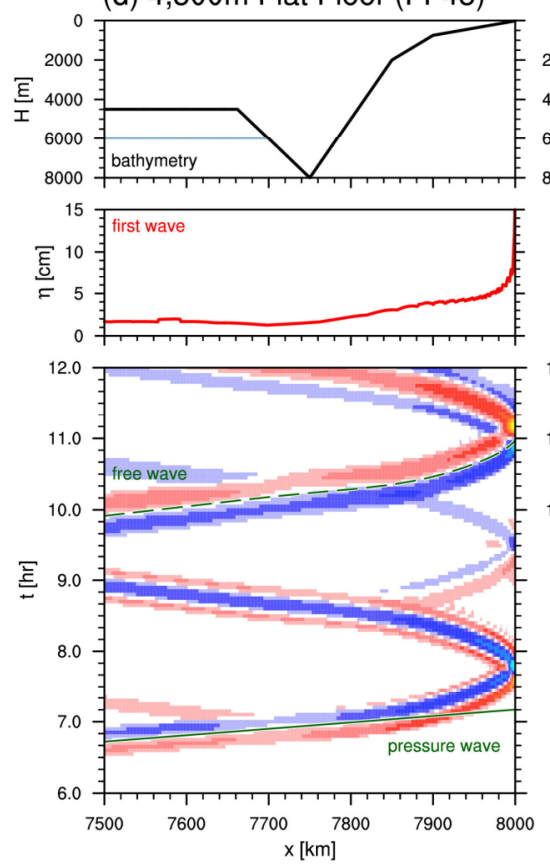

(c) $6,000 \mathrm{~m}$ Flat Floor (FF60)
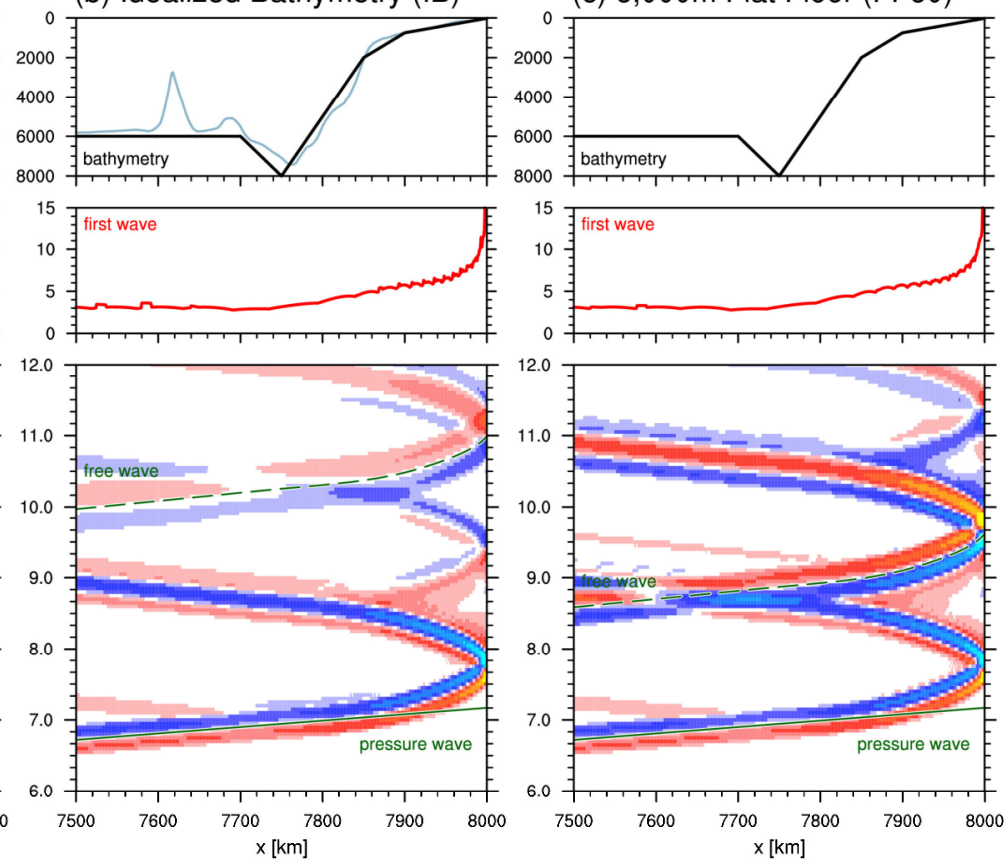

(e) No Trench (NoT)

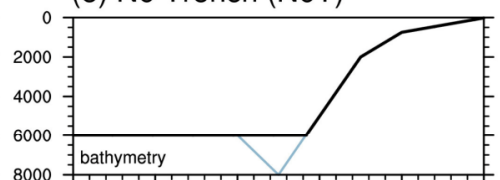

(f) No Shelf (NoS)
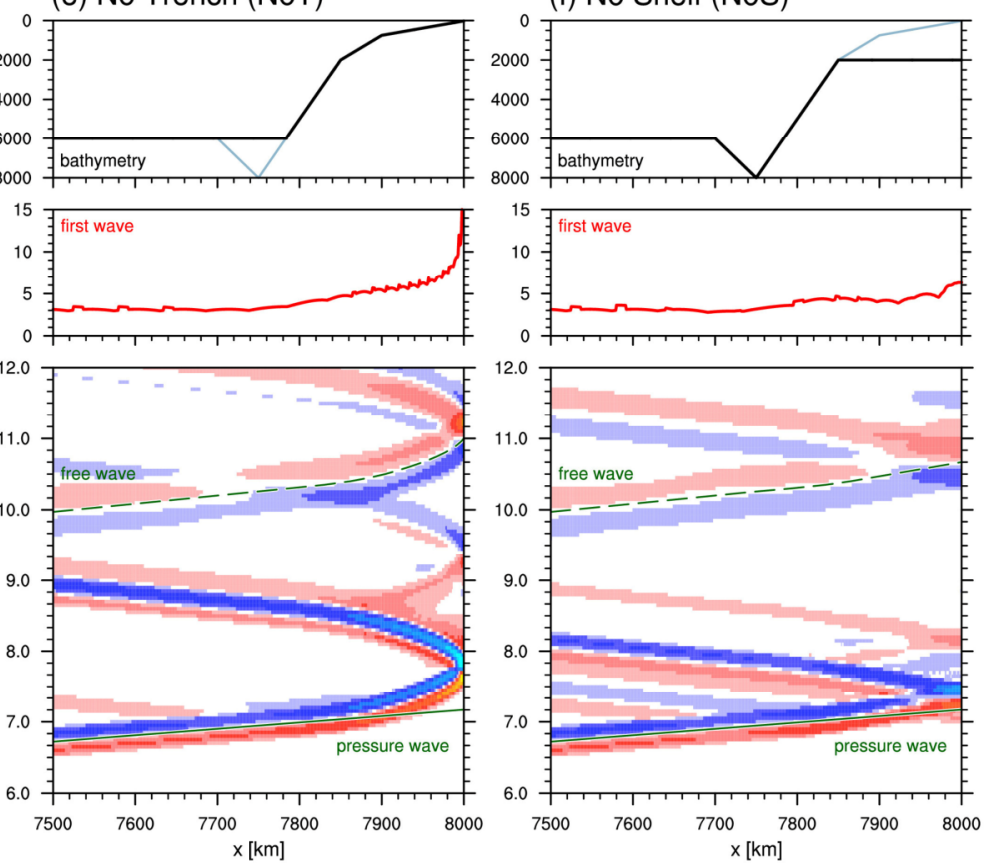

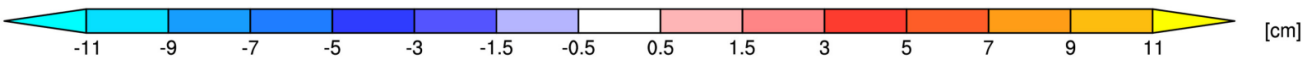

Fig. 5. Same as in Fig. 4 but for the domain near the coast $(7,500 \mathrm{~km} \leqq x \leqq 8,000 \mathrm{~km})$.

propagating rightward from $x=0$ and their reflected waves near the coast are generated (Fig. 4b). Comparing the sea-level anomalies at the coast $(x=8,000$ $\mathrm{km}$ ) in both experiments (Figs. 6a and 6b), the IB experiment reproduces well the first wave seen in the
RB experiment. The first wave arrives about 30 minutes later than the pressure wave and about 4 hours earlier than the free wave propagating throughout $8,000 \mathrm{~km}$, both of which are consistent with the observations (Fig. 1). The first wave is synchronized 
with the pressure wave while travelling over the ba$\sin$. When it reaches the continental slope, however, the coupling breaks and it begins to propagate as a free wave (Fig. 5b), resulting in the late arrival behind the pressure wave at the coast. The disconnection of the forced wave from atmospheric forcing over shoaling slopes was also demonstrated in numerical experiments by Vilibić (2008) and Chen and Niu (2018).

In contrast to the similarity in the first wave between the RB and IB experiments, the latter shows much weaker subsequent sea-level oscillations (Fig. $6 \mathrm{~b})$. This lack of following waves suggests that the oscillatory behavior is a manifestation of the effect of relatively small-scale topography. However, since such small-scale topography represented in the RB experiment mostly reflects isolated seamounts rather than ridges and waves can propagate around them in the real world, the effect may be exaggerated in this one-dimensional model. Nevertheless, the effect of relatively large-scale topography, such as the IzuBonin Arc and the Kyushu-Palau Ridge, may have stronger impacts on regions where the forced wave has crossed over them before arriving.

If the ocean basin is flattened to $6,000 \mathrm{~m}$, the amplitude of the first wave is nearly constant while propagating over the basin (Fig. 4c), whereas it monotonically grows in IB experiments (Fig. 4b). This growth with increasing depth is explained by the near-Proudman resonance. According to previous studies (Proudman 1929; Vilibić 2008; Williams et al. 2021), the sea-level displacement $\eta$ can be written as a superposition of a forced wave, a rightward free wave and a leftward free wave as

$$
\begin{aligned}
\eta(t, x)= & \\
-\frac{1}{\rho g}\left\{\frac{P(x-V t)}{1-F r^{2}}-\frac{P(x-c t)}{2(1-F r)}\right. & \left.-\frac{P(x+c t)}{2(1+F r)}\right\},
\end{aligned}
$$

where the Froud number $\mathrm{Fr}$ is defined as $\mathrm{V} / \mathrm{c}$. The amplitude of the forced wave is $\eta_{0} /\left(1-F r^{2}\right)$, where $\eta_{0}=-P / \rho g$ is the static sea-level change in response to a steady pressure anomaly $(\sim 2 \mathrm{~cm}$ for $2 \mathrm{hPa})$. At $H=6,000 \mathrm{~m}$, the amplitude of the forced wave is thus estimated to be $\sim 3.2 \mathrm{~cm}$, which is equivalent to that of the simulated forced wave (Fig. 4c). In the FF45 case, the forced wave is weaker with the amplitude of $\sim 1.7 \mathrm{~cm}$ (Fig. $4 \mathrm{~d}$ ), again consistent with the theoretical estimation. Though the seafloor has a gentle slope in the IB experiment, the amplitude is practically determined by the deepest region, and thus, the first wave at the continental slope exhibit the same amplitudes between the IB and FF60 experiments (Figs. 5b and c, 6b and c).

On the basis of Eq. (3), one may expect th at the trench can act to amplify the wave significantly. However, Figs. $6 \mathrm{~b}$ and $6 \mathrm{e}$ reveal that the amplitude remains unchanged in the NoT experiment. This insensitivity to the trench can be attributed to the narrowness of the trench relative to the wavelength of pressure forcing.

In all of the experiments, the first wave undergoes significant amplification near the coast (Figs. 5a-e). This amplification is mainly due to the shoaling effect on long waves: deceleration of the phase speed shortens their wavelength and grows their height to conserve the energy flux. This effect makes the wave amplitude inversely proportional to the fourth root of the depth, which is referred to as the

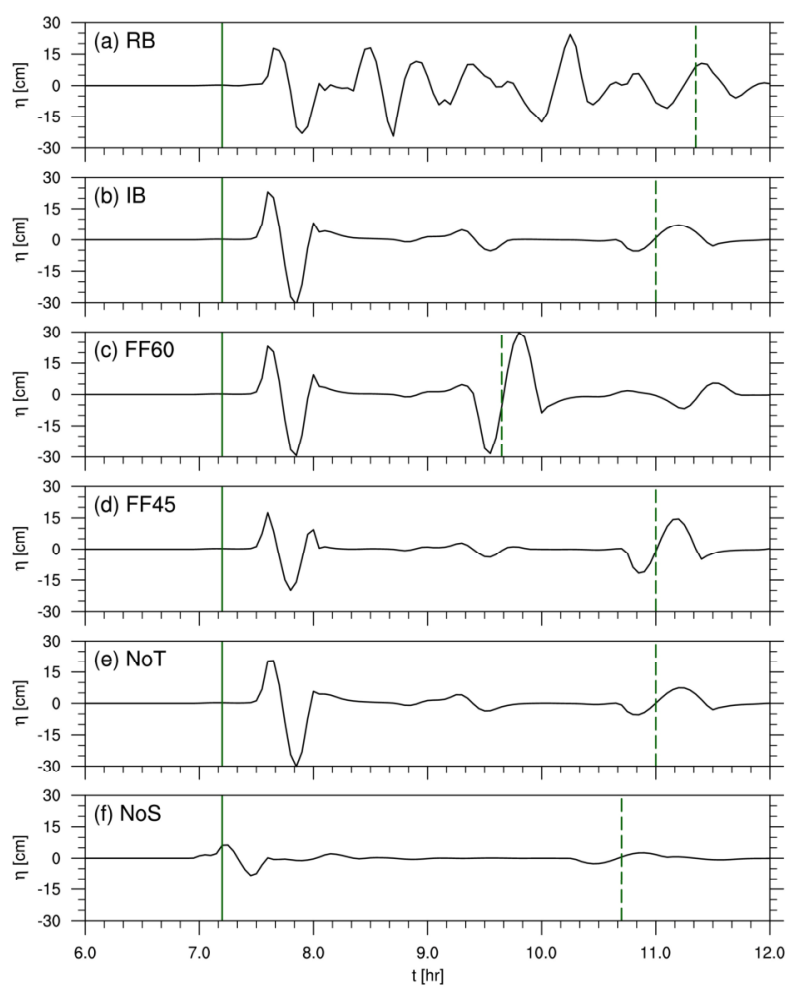

Fig. 6. Simulated sea-level changes at the coast $(x=8,000 \mathrm{~km})$ in the (a) RB, (b) IB, (c) FF60, (d) FF45, (e) NoT, and (f) NoS experiment. Green solid and dashed lines indicate the arri-val time of the pressure wave and the free wave that departs from $x=0$ at $t=0$. 
Green's law, together with the contribution from narrowing intervals of wave rays (Lamb 1932) This law is widely used to analyze not only meteotsunamis but also tectonically-induced tsunamis (e.g., Sandambata et al. 2018). Shallowing from the 6,000-m to $20-$ $\mathrm{m}$ depth results in the amplification by a factor of $\sqrt[4]{6,000 \mathrm{~m} / 20 \mathrm{~m}}=\sim 4.2$. In the IB experiment, the amplitude just before reaching the trench $(x=7,500$ $\mathrm{km}, H=6,000 \mathrm{~m})$ is $\sim 3.2 \mathrm{~cm}$, so the amplitude at $x=8,000 \mathrm{~km}(H=20 \mathrm{~m})$ is estimated to be $\sim 13.2 \mathrm{~cm}$. Since $u=0$ is now required as the boundary condition, it doubles to be $\sim 26.4 \mathrm{~cm}$ at the coast, which is consistent with the simulated first wave in the IB experiment (Fig. 6b). Indeed, no significant amplification of waves is reproduced in the NoS experiment (Figs. 5f and 6f).

\section{Conclusions}

After the Hunga-Tonga eruption in 2022, tsunami-like sea-level fluctuations were observed in Japan, much earlier than expected from the arrival of oceanic long waves tectonically excited by the eruption. Indeed, the atmospheric pressure disturbance of about $2 \mathrm{hPa}$ propagating at about $310 \mathrm{~m} \mathrm{~s}^{-1}$ was observed about 30 minutes before this tsunami, which was presumably generated by the eruption. Therefore, in this study, we have made a plausible explanation by assuming that this pressure disturbance has forced the tsunami-like waves.

To explain the nature of the observed sea-level fluctuations as simply as possible, we have performed six numerical experiments with different depth profiles by using a one-dimensional shallowwater model. Based on the simulations, we have reached the following conclusions about this tsunami-like waves:

- The tsunami-like waves were forced by atmospheric pressure waves propagating faster than oceanic long waves, resulting in the arrival of the waves several hours earlier than predicted.

- The pressure-forced wave was synchronized with the atmospheric forcing over the ocean basin, before it separated from the forcing and propagated at the speed of free waves on the continental slope. Thus, the arrival of the first wave at the coast is delayed by a few tens of minutes behind the pressure wave.

- The forced wave is amplified by the near-
Proudman resonance over the $6,000-\mathrm{m}$ class basin and the shoaling effect (Green's law) near the coast.

- The trench is too narrow for the Proudman resonance to be effective, so it has little effect on the amplitude of the first wave.

- The topography, such as seamounts, island arcs and ridges, and the reflection between the coast and trench may have contributed to the long-lasting sea-level change following the first wave.

We note that the model we used oversimplifies the real world and cannot explain all aspects of the observed phenomenon, although we consider that it captures the essence. Since the one-dimensional model does not have coastal topography in the direction perpendicular to wave propagation, we cannot evaluate amplification mechanisms though energy flux convergence into shoals, harbor resonance and interaction with edge waves, which are important in ordinary meteotsunamis (e.g., Hibiya and Kajiura 1972; Monserrat et al. 2006; Fukuzawa and Hibiya 2020). Moreover, oceanic waves directly forced by volcano and/or caldera collapses and atmospheric waves slower than the speed of sound may have also arrived several hours later, as pointed out by Harkrider and Press (1967) for the Krakatoa eruption. Numerical simulations with more realistic configurations will shed light on these issues in future studies.

This study has pointed out the importance of relatively deep seafloor to the amplification of the meteotsunami forced by atmospheric pressure disturbances. Because the pressure waves associated with a large volcanic eruption spread globally, regions with the 6,000-m class basin in the vicinity may have undergone a similar phenomenon when the pressure waves passed over such a deep ocean area.

\section{Acknowledgements}

The first author is supported by the Arctic Challenge for Sustainability II (ArCS II; JPMXD1420318865) and by JSPS-Kakenhi 19H05702. The second author is supported by JSPS-Kakenhi 20K14554. The bathymetry data is provided by GEBCO Compilation Group (https://doi.org/10.5285/c6612cbe-50b3-0cff-e053-

$6 \mathrm{c} 86 \mathrm{abc09f8f})$. We would like to thank Weathernews Inc. for their generous decision of letting researchers use their air pressure data. We would also like to thank Amane Nakamura for helping us download the observed sea-level data. 


\section{References}

Chen, Y., and X. Niu, 2018: Forced wave induced by an atmospheric pressure disturbance moving towards shore. Cont. Shelf Res., 160, 1-9. https://doi.org/10.1016/j.csr.2018.03.007.

Fukuzawa, K., and T. Hibiya, 2020: The amplification mechanism of a meteo-tsunami originating off the western coast of Kyushu Island of Japan in the winter of 2010. J. Oceanogr., 76, 169-182. https://doi.org/10.1007/s10872-019-00536-3.

Harkrider, D., and F. Press, 1967: The Krakatoa air-sea waves: An example of pulse propagation in coupled systems. Geophys. J. Int., 13, 149-159. https://doi.org/10.1111/j.1365-246X.1967.tb02150.x.

Hibiya, T., and K. Kajiura, 1982: Origin of the Abiki phenomenon (a kind of Seiche) in Nagasaki Bay. $J$. Oceanogr. Soc. Japan, 38, 172-182. https://doi.org/10.1007/BF02110288.

Kubota, T., T. Saito, N. Y. Chikasada, and O. Sandanbata, 2021: Meteotsunami observed by the deep-ocean seafloor pressure gauge network off northeastern Japan. Geophys. Res. Lett., 48(21), e2021GL094255. https://doi.org/10.1029/2021GL094255.

Lamb, H., 1932: Hydrodynamics, Sixth edition. Cambridge University Press, 273-275 pp.

Monserrat, S., I. Vilibić, and A. B. Rabinovich, 2006: Meteotsunamis: atmospherically induced destructive ocean waves in the tsunami frequency band. Nat. Hazards Earth Syst. Sci., 6, 1035-1051. https://doi.org/10.5194/nhess-6-1035-2006.

Press, F., and D. Harkrider, 1966: Air-sea waves from the explosion of Krakatoa. Science, 154(3754), 13251327. https://doi.org/10.1126/science.154.3754.1325.

Proudman, J., 1929: The effects on the sea of changes in atmospheric pressure. Geophys. Suppl. Mon. Not. R. Astron. Soc., 2(4), 197-209. https://doi.org/10.1111/j.1365-246X.1929.tb05408.x.

Vilibić, I., 2008: Numerical simulations of Proudman resonance. Cont. Shelf Res., 28, 574-581. https://doi.org/10.1016/j.csr.2007.11.005.

Sandanbata, O., S. Watada, K. Satake, Y. Fukao, H. Sugioka, A. Ito, and H. Shiobara, 2018: Ray tracing for dispersive tsunamis and source amplitude estimation based on Green's law: Application to the 2015 volcanic tsunami earthquake near Torishima, south of Japan. Pure Appl. Geophys., 175, 1371-1385. https://doi.org/10.1007/s00024-017-1746-0.

Williams, D. A., K. J. Horsburgh, D. M. Schultz, and C. W. Hughes, 2021: Proudman resonance with tides, bathymetry and variable atmospheric forcings. Nat.
Hazards,

106, $1169-1194$. https://doi.org/10.1007/s11069-020-03896-y. 